\title{
Indexação na SciELO: uma etapa cumprida e não a meta final
}

Após cerca de 2 anos do início das mudanças requeridas, anunciamos o cumprimento do compromisso de indexar a RBCP no Sistema SciELO - Scientific Electronic Library Online.

O modelo SciELO é produto da cooperação entre a FAPESP - Fundação de Amparo à Pesquisa do Estado de São Paulo, BIREME - Centro Latino-Americano e do Caribe de Informação em Ciências da Saúde, instituições nacionais e internacionais relacionadas com a comunicação científica e editores científicos. Um projeto piloto, envolvendo 10 periódicos brasileiros de diferentes áreas do conhecimento, foi desenvolvido com êxito entre março de 1997 e maio de 1998, com o desenvolvimento e a avaliação de uma metodologia adequada para a publicação eletrônica na Internet. Desde junho de 1998, o projeto opera regularmente, incorporando novos títulos de periódicos e expandindo sua atuação para outros países. A partir de 2002, o Projeto conta com o apoio do CNPq - Conselho Nacional de Desenvolvimento Científico e Tecnológico.

A SciELO foi criada com o objetivo de aumentar a visibilidade dos periódicos nacionais, igualando-os aos padrões internacionais de qualidade. A SciELO, portanto, é uma biblioteca eletrônica e também um sistema indexador de periódicos. Diferentemente de indexadores simples, ela oferece o conteúdo completo dos periódicos que pertencem ao seu acervo, garantindo acessibilidade pública aos mesmos.

A entrada da RBCP na SciELO ainda permitirá a ascensão da nossa Revista no sistema Qualis/CAPES de avaliação de periódicos para categoria B4, atraindo maior número de pesquisadores interessados em divulgar seus estudos de mestrado e doutorado. Em última análise, o ingresso na SciELO pode ser considerado um certificado da qualidade do periódico, restrito a um seleto grupo de publicações.

O processo de inclusão no Sistema foi complexo e exigiu, além da adoção de uma série de normas rígidas, o compromisso do cumprimento de metas a médio prazo que modificarão positivamente o fluxo da RBCP. É importante neste momento ressaltar a dedicação de todos os profissionais envolvidos neste processo, incluindo o Corpo Editorial e Administrativo da SBCP, que foram fundamentais para a obtenção dos objetivos propostos.

Nos primeiros momentos após a intenção assumida em melhorar a qualidade de nossa Revista e obter outras indexações, foram tomadas medidas que possibilitaram atingir os critérios para submissão à SciELO, graças ao apoio obtido junto à Diretoria da SBCP, que conjuntamente vislumbrou a relevância destas implementações frente à especialidade.

As medidas requeridas exigiram modificações no corpo editorial, criação do sistema integrado e computadorizado para submissão de artigos científicos, agilidade no fluxo de artigos e respeito à regularidade nas edições, bem como incremento no número de artigos originais publicados por fascículo.

Todas estas mudanças obviamente levaram à melhoria na qualidade da RBCP, paralelamente ao aumento na quantidade de artigos publicados.

Para a aceitação da RBCP no Sistema SciELO estas alterações não foram suficientes em uma primeira avaliação, havendo a necessidade de persistir na implementação de mudanças e, paralelamente, solicitar a revisão do parecer negativo inicialmente obtido. Em dezembro de 2010, o novo parecer da SciELO foi favorável, assumindo-se o compromisso de realizar nos próximos 12 meses mudanças adicionais que incluirão a publicação da Revista em idioma inglês (processo que já se encontrava em implementação) e o aprimoramento do sistema de revisão de artigos no que diz respeito à participação dos revisores ad hoc.

Uma vez indexado o periódico, a SciELO executa um processo contínuo de acompanhamento, o que implica na manutenção dos requisitos que garantiram sua indexação, bem como na melhoria progressiva de qualidade.

Felizmente todas as exigências acarretarão melhoria de qualidade e divulgação.

A mudança do idioma é exigência da SciELO e, certamente, colocará a RBCP no cenário internacional. A edição em português, no entanto, não será suprimida e a RBCP será bilíngue na sua publicação eletrônica na Internet. O sistema de revisão por pares (peer review) será aperfeiçoado e envolverá também maior número de revisores independentes, cumprindo a segunda exigência da SciELO. Portanto, nosso trabalho não está finalizado, ao contrário, ele foi apenas iniciado e uma etapa está cumprida. A meta final certamente é a indexação nos sistemas internacionais, incluindo Pubmed/Medline, Thomson-Reuters (ISI) e Scopus. 